\title{
Erratum
}

\section{ERRATUM TO 'A CROSS-SECTIONAL SURVEY ON DOG ECOLOGY AND DOG ANTI-RABIES VACCINATION COVERAGE IN SELECTED AREAS IN SRI LANKA' [S.L.Vet.J. 2017, 64:1(A): 1-9]}

\author{
R.M.S. Pimburage ${ }^{1}$, P.A.L. Harischandra ${ }^{1}$, M. Gunatilake ${ }^{2}$, D.N. Jayasinhe ${ }^{1}$, \\ A. Balasuriya ${ }^{3}$, R.M.S.K. Amunugama ${ }^{4}$ \\ ${ }^{\prime}$ Public Health Veterinary Services, Ministry of Health, Sri Lanka \\ ${ }^{2}$ Department of Physiology, Faculty of Medicine, University of Colombo, Sri Lanka \\ ${ }^{3}$ Faculty of Medicine, General Sir John Kotelawala Defence University, Sri Lanka \\ ${ }^{4}$ Ministry of Health, Sri Lanka
}

\section{MATERIALS \& METHODS}

\section{Study design and sampling}

This was a cross-sectional analytical study conducted in the year 2013, using the capture recapture method. The study was carried out in two provinces (Western and Southern) of Sri Lanka. Two Divisional Secretariats (DS) from each province were selected based on the average human population (http://www.statistics.gov.lk). Figure 1 illustrates the districts, divisional secretariats (DS) and public health inspector (PHI) areas selected for this study.

\section{RESULTS}

\section{Populations captured and recaptured}

A total of 2508 dogs presented to temporary vaccination centres during the period of survey was marked with red collars after vaccination. Total number of family members (number of members in the families in which the dogs belong) recorded at that time was 8690 . From the 2933, owned, free-roaming dogs and freeroaming dogs with undetermined ownership counted through the transect line count, 1413 had been marked at

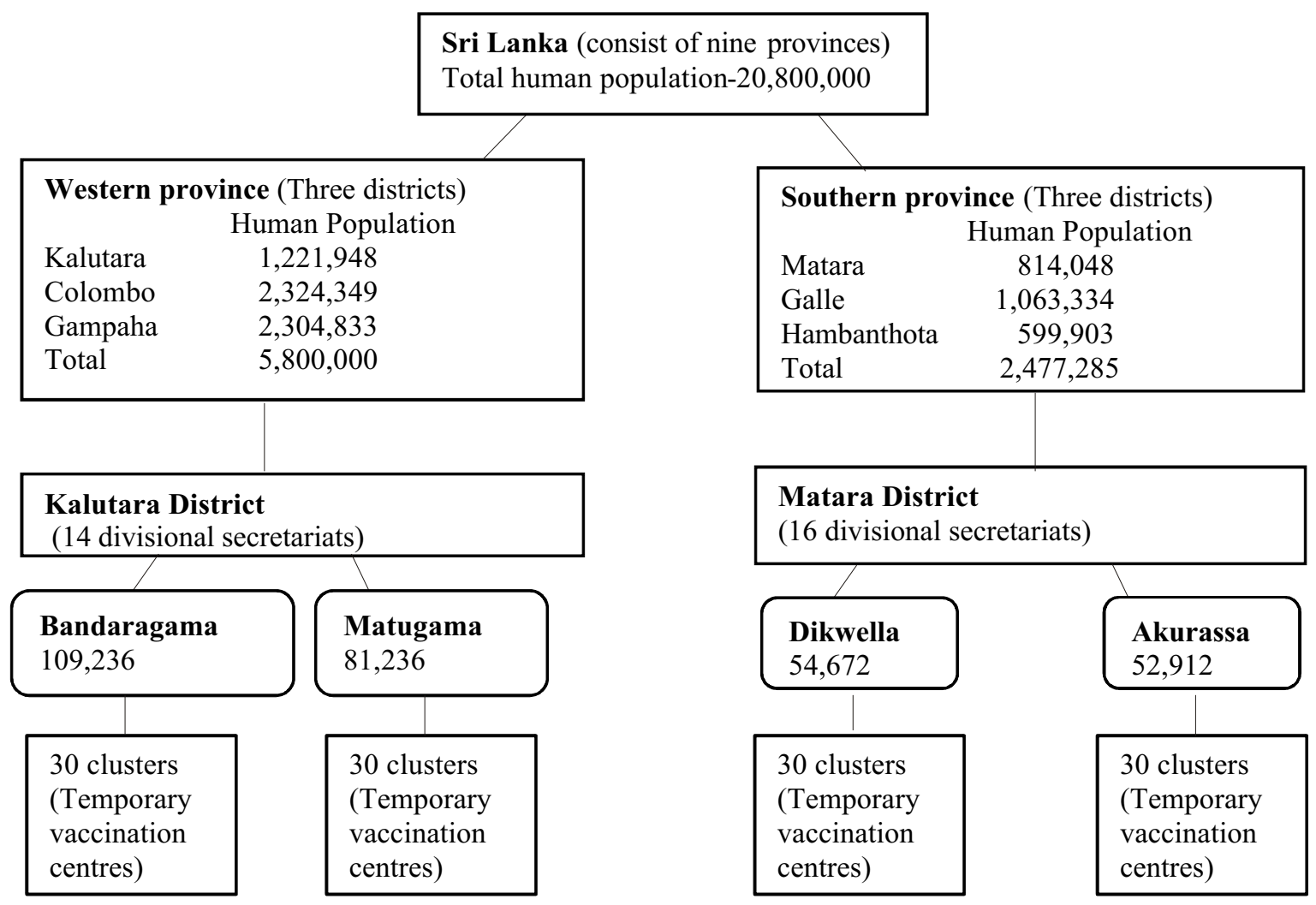

Figure 1: Flow chart indicating sampling 
the temporary vaccination centre (Table 1).

Table 1: Information obtained from capture and recapture data of human population and dog population

\begin{tabular}{lc}
\hline Variable & Numbers \\
\hline $\begin{array}{l}\text { Captured(marked) Sample } \\
\text { Dog }\end{array}$ & 2508 \\
Human & 8690 \\
& \\
Recaptured & \\
Dogs & 838 \\
$\quad$ Number of dogs through household survey & 2933 \\
$\quad$ Number of dogs through transect line study & 1413 \\
$\quad$ Number of marked dogs through transect line study & \\
Human & 8622 \\
$\quad$ Number of people through household survey & \\
\hline
\end{tabular}

There were 2207 households in the four DS divisions and all were included in the study during the recapture phase. There were 838 dogs and the mean age of the sample dog population was 3.5 years.

\section{Management of dogs by the owners}

During the household survey, it was found that $552(66 \%)$ dogs were kept restrained by caging 245 (29\%) or tying 307 (37\%). Remaining 286 (34\%) owned dogs were allowed to roam freely during the day. Among 552 confined dogs, 425 (77\%) were vaccinated and out of 286 unconfined owned dogs, only $154(53.8 \%)$ were vaccinated (Table 2$)$. The percentage of females $(34.3 \%)$ were higher than that of males $(29.1 \%)$ in free-roaming dogs (dogs who are allowed to roam freely out of the household premises without restrictions).

Table2: Household information on 838 dogs obtained from respondents in 2207 households in study areas

\begin{tabular}{lccc}
\hline Variable & Frequency & Percentage (\%) & ARV coverage \\
\hline $\begin{array}{l}\text { Households with dogs } \\
\text { Sex }\end{array}$ & 0.375 & 37.5 & \\
$\quad$ Male & 662 & 78.9 & $69 \%$ \\
$\quad$ Female & 176 & 21.1 & $66 \%$ \\
Age & & & \\
$<1$ year & 132 & 15.7 & $65 \%$ \\
$\quad$ 1 year & 706 & 84.2 & $65 \%$ \\
Breed & & & \\
$\quad$ Local & 759 & 90.5 & $68 \%$ \\
$\quad$ Other & 79 & 9.4 & $78 \%$ \\
Rearing method & & & \\
$\quad$ Caged & 245 & 29.2 & $83 \%$ \\
Leashed & 307 & 36.6 & $71 \%$ \\
Free & 286 & 34.1 & $53 \%$ \\
\hline
\end{tabular}

The original online version of the above article contained errors which have been rectified in the relevant sections by including Tables 1 and 2. The editorial committee regrets for any inconvenience caused. 